\title{
MR
}

\section{Association between the pre-miR-196a2 rs11614913 polymorphism and gastric cancer susceptibility in a Chinese population}

\author{
M. Li, R.J. Li, H. Bai, P. Xiao, G.J. Liu, Y.W. Guo and J.Z. Mei \\ Department of Medical Oncology, Zhengzhou People's Hospital, \\ Zhengzhou, China \\ Corresponding author: J.Z. Mei \\ E-mail: jiangtbt@163.com \\ Genet. Mol. Res. 15 (2): gmr.15027516 \\ Received August 25, 2015 \\ Accepted January 6, 2016 \\ Published April 27, 2016 \\ DOI http://dx.doi.org/10.4238/gmr.15027516
}

\begin{abstract}
We did a case-control study to provide a more comprehensive evaluation of the association of the pre-miR-196a2 rs11614913 polymorphism with gastric cancer. Between January 2013 and December 2014, 182 patients newly diagnosed with primary gastric cancer and 182 control subjects were recruited at Zhengzhou People's Hospital. For SNP genotyping, we used the Assay Designer 3.1 to design the primers of polymerase chain reaction. Using the chisquare test, we found that patients with gastric cancer were more likely to be alcohol drinkers $\left(\chi^{2}=4.4, \mathrm{P}=0.04\right)$, to have a family history of cancer in the first relatives $\left(\chi^{2}=5.29, \mathrm{P}=0.02\right)$, and to be infected with Helicobacter pylori $\left(\chi^{2}=23.39, \mathrm{P}<0.001\right)$. A significant difference in the genotype distributions of rs11614913 was observed in our study $\left(\chi^{2}=6.66, \mathrm{P}=0.04\right)$. By logistic regression analysis, we found that the $C C$ genotype of rs11614913 was associated with an increased risk of gastric cancer in a codominant model $(\mathrm{OR}=2.68,95 \% \mathrm{CI}=1.17$ 6.44). By stratification analysis, we found that the $C C$ genotype was associated with a strongly increased risk of gastric cancer in drinkers when compared with the $T T+T C$ genotype $(\mathrm{OR}=5.63,95 \% \mathrm{CI}=1.54$ -
\end{abstract}


30.76). In conclusion, the results of our study suggest an association between the rs11614913 gene polymorphism and an elevated risk of gastric cancer, especially in drinkers.

Key words: Gastric cancer; Pre-miR-196a2; Rs11614913; Genotype

\section{INTRODUCTION}

An estimated one million new cases of gastric cancer were diagnosed in 2012 (952,000 cases, $6.8 \%$ of the total newly diagnosed cancer cases), making it the fifth most common malignancy in the world, after cancers of the lung, breast, colorectum, and prostate (IARC, 2012). Various risk factors are involved in the development of gastric cancer, including environmental factors and microbial infections (Ang and Fock, 2014; Daniyal et al., 2015; Fang et al., 2015). Although Helicobacter pylori infection has been identified to play an important role in the development of gastric cancer, the precise etiology of gastric cancer remains unclear (Graham and Yamaoka, 2000; Ang and Fock, 2014; Fang et al., 2015). Not all patients positive for Helicobacter pylori infection develop gastric cancer during their lifetime, which suggests that genetic factors contribute to the development of this cancer. Many single-nucleotide polymorphisms (SNPs) have been reported to be associated with gastric carcinogenesis (Kamangar et al., 2006; Yuzhalin, 2011).

Rs11614913 ( $\mathrm{T}>\mathrm{C})$ is a common variant in pre-miR-196a2 that plays a role in the development of multiple cancer types, including gastric cancer (Peng et al., 2014; Ni et al., 2015; Nikolić et al., 2015; Qi et al., 2015; Wu et al., 2015). Several studies have evaluated the effect of this polymorphism on gastric cancer risk in different populations, but the results are inconsistent. Therefore, we did a case-control study to provide a more comprehensive evaluation of the association of this polymorphism with gastric cancer risk.

\section{MATERIAL AND METHODS}

\section{Study population}

For our hospital-based case-control designed study, we recruited 182 patients who were newly diagnosed with histopathologically confirmed primary gastric cancer at the Zhengzhou People's Hospital between January 2013 and December 2014. Patients who had primary tumors other than gastric cancer, tumors of an unknown origin, or any histopathological diagnosis other than gastric cancer were excluded.

A total of 182 controls were randomly selected from individuals who received health check-ups in our hospital, and the controls were matched for age and sex with the gastric cancer patients. Controls who had any type of digestive disease were excluded from this study, including atrophic gastritis, inflammation, hyperplasia, and intestinal metaplasia.

The demographic characteristics, including sex, age, alcohol consumption, and smoking status, were collected via a self-designed questionnaire. The clinical characteristics, including histological types and TNM stage, were collected from the medical records. $H$. pylori infection was detected by serology, histological examination, or the urea breath test. Written informed consent was obtained from each participant. The study was approved by the Institutional Research Ethics Committee of the Zhengzhou People's Hospital. 


\section{DNA extraction and genotyping}

For DNA extraction, approximately $2 \mathrm{~mL}$ of peripheral venous blood was collected from each participant and stored at $-20^{\circ} \mathrm{C}$ in non-anticoagulant, plexiglass tubes. Genomic DNA was extracted using the ClotBlood DNA kit (Cwbio, Beijing, China) and an ultraviolet spectrophotometer (Beckman, USA) was used to analyze the concentration and purity of the extracted DNA. For SNP genotyping, we used the Assay Designer 3.1 to design polymerase chain reaction (PCR) primers. The primers for rs 11614913 were designed using Sequenom Assay Design 3.1 software. The forward and reverse primers were 5'-CCC CTT GGG TTG TGG TCC AGA TA-3' and 5'-CGAAAA GGC ACT GAT GTAACT GGC-3', respectively. The following PCR conditions were applied: an initial denaturation at $95^{\circ} \mathrm{C}$ for $5 \mathrm{~min}$, followed by 30 cycles of annealing at $62^{\circ} \mathrm{C}$ for $60 \mathrm{~s}$ and extension at $72^{\circ} \mathrm{C}$ for $60 \mathrm{~s}$, and a final extension at $72^{\circ} \mathrm{C}$ for $10 \mathrm{~min}$. The PCR products were stained with ethidium bromide and analyzed under ultraviolet light on a $2 \%$ agarose gel.

\section{Statistical analysis}

Variables of demographic characteristics are reported as frequencies and percentages of study subjects. Differences in genotype and allele frequencies between cases and controls were evaluated using the chi-square test. Hardy-Weinberg equilibrium (HWE) was used to evaluate deviations between the observed and ideal Hardy-Weinberg frequencies in controls. The role of the rs11614913 polymorphism in the development of gastric cancer was evaluated by conditional logistic regression, and the results were expressed in terms of odds ratio's (ORs) and 95\% confidence intervals (CIs). All $\mathrm{P}$ values were two sided, and $\mathrm{P}<0.05$ was considered statistically significant. All statistical analyses were performed using the SPSS statistical software package, version 16.0 (SPSS Inc., Chicago, IL, USA).

\section{RESULTS}

The demographic and clinical characteristics of patients with gastric cancer and control subjects are shown in Table 1. Based on the chi-square test, patients with gastric cancer were more likely to be alcohol drinkers $\left(\chi^{2}=4.4, \mathrm{P}=0.04\right)$, have a family history of cancer in firstdegree relatives $\left(\chi^{2}=5.29, \mathrm{P}=0.02\right)$, and be infected with Helicobacter pylori $\left(\chi^{2}=23.39, \mathrm{P}<\right.$ $0.001)$. However, no significant differences were found between patients and controls in terms of $\operatorname{sex}\left(\chi^{2}=0.01, \mathrm{P}=0.92\right)$, age $\left(\chi^{2}=0.00, \mathrm{P}=1.00\right)$, or tobacco smoking $\left(\chi^{2}=0.18, \mathrm{P}=0.67\right)$.

The genotype distribution of rs11614913 in the control group conformed to the HWE $(\mathrm{P}=$ 0.27 ) (Table 2). A significant difference in the genotype distributions of rs11614913 was observed in our study $\left(\chi^{2}=6.66, \mathrm{P}=0.04\right)$. By logistic regression analysis, we found that the $C C$ genotype of rs11614913 was associated with an increased risk of gastric cancer in a codominant model $(\mathrm{OR}=$ $2.68,95 \% \mathrm{CI}=1.17-6.44)$. In the recessive model, the $C C$ genotype was observed to be correlated with an elevated increased risk of gastric cancer when compared with the $T T+T C$ genotype.

The association between rs11614913 polymorphism and the development of gastric cancer was stratified based on sex, age, alcohol and tobacco consumption, family history of cancer in first-degree relatives, and Helicobacter pylori infection (Table 3). By stratification analysis, we found that the $C C$ genotype was associated with a strongly increased risk of gastric cancer in drinkers when compared with the $T T+T C$ genotype $(\mathrm{OR}=5.63,95 \% \mathrm{CI}=1.54-30.76)$. 
Table 1. Demographic characteristics of gastric cancer patients and control subjects.

\begin{tabular}{|c|c|c|c|c|c|c|}
\hline Variables & Patients & $\%$ & Controls & $\%$ & $\chi^{2}$-test & P value \\
\hline \multicolumn{7}{|l|}{ Age (years) } \\
\hline$<55$ & 103 & 56.59 & 104 & 57.14 & & \\
\hline$\geq 55$ & 79 & 43.41 & 78 & 42.86 & 0.01 & 0.92 \\
\hline \multicolumn{7}{|l|}{ Gender } \\
\hline Female & 58 & 31.87 & 58 & 31.87 & & \\
\hline Male & 124 & 68.13 & 124 & 68.13 & 0.00 & 1.00 \\
\hline \multicolumn{7}{|c|}{ Alcohol drinkers } \\
\hline Never & 83 & 45.60 & 103 & 56.59 & & \\
\hline Ever & 99 & 54.40 & 79 & 43.41 & 4.4 & 0.04 \\
\hline \multicolumn{7}{|c|}{ Tobacco smoking } \\
\hline Never & 104 & 57.14 & 108 & 59.34 & & \\
\hline Ever & 78 & 42.86 & 74 & 40.66 & 0.18 & 0.67 \\
\hline \multicolumn{7}{|c|}{ Family history of cancer in the first relatives } \\
\hline No & 167 & 91.76 & 177 & 97.25 & & \\
\hline Yes & 15 & 8.24 & 5 & 2.75 & 5.29 & 0.02 \\
\hline \multicolumn{7}{|c|}{ Helicobacter pylori } \\
\hline Negative & 75 & 41.21 & 121 & 66.48 & & \\
\hline Positive & 107 & 58.79 & 61 & 33.52 & 23.39 & $<0.001$ \\
\hline \multicolumn{7}{|c|}{ Lauren's classification } \\
\hline Intestinal & 78 & 42.86 & & & & \\
\hline Diffuse & 104 & 57.14 & & & & \\
\hline \multicolumn{7}{|l|}{ TNM stage } \\
\hline I-II & 83 & 45.60 & & & & \\
\hline III-IV & 99 & 54.40 & & & & \\
\hline
\end{tabular}

Table 2. Association between the rs 11614913 polymorphism and the development of gastric cancer.

\begin{tabular}{l|c|c|c|c|c|c|c|c|c}
\hline Genotype & Patients & $\%$ & Controls & $\%$ & P for HWE & $\chi^{2}$-test & P value & OR (95\%CI $)^{1}$ & P value \\
\hline Codominant & & & & & & & & & \\
\hline TT & 75 & 41.2 & 92 & 50.6 & & & & Ref. (1.0) & - \\
\hline CT & 83 & 45.7 & 79 & 43.2 & & & & $1.29(0.82-2.04)$ & 0.25 \\
\hline CC & 24 & 13.1 & 11 & 6.2 & 0.27 & 6.66 & 0.04 & $2.68(1.17-6.44)$ & 0.01 \\
\hline Dominant & & & & & & & & & \\
\hline TT & 75 & 41.2 & 92 & 50.6 & & & & Ref. (1.0) & - \\
\hline TC+CC & 107 & 58.8 & 90 & 49.4 & & 3.19 & 0.07 & $1.46(0.94-2.25)$ & 0.07 \\
\hline Recessive & & & & & & & & & \\
\hline TT+TC & 158 & 86.9 & 171 & 93.8 & & & & Ref. $(1.0)$ & - \\
\hline CC & 24 & 13.1 & 11 & 6.2 & & 5.34 & 0.02 & $2.36(1.07-5.51)$ & 0.02 \\
\hline
\end{tabular}

${ }^{1}$ Adjusted for gender, age, alcohol drinking, family history of cancer in the first relatives and Helicobacter pylori infection.

Table 3. Interaction between the rs 11614913 polymorphism and demographic characteristics for gastric cancer risk.

\begin{tabular}{|c|c|c|c|c|c|c|}
\hline \multirow{2}{*}{ Variables } & \multicolumn{2}{|c|}{ Patients } & \multicolumn{2}{|c|}{ Controls } & \multirow[t]{2}{*}{ OR $(95 \% \mathrm{CI})$} & \multirow{2}{*}{ P value } \\
\hline & $\mathrm{TT}+\mathrm{TC}$ & $\mathrm{CC}$ & $\mathrm{TT}+\mathrm{TC}$ & $\mathrm{CC}$ & & \\
\hline \multicolumn{7}{|l|}{ Age (years) } \\
\hline$<55$ & 88 & 15 & 97 & 7 & $2.36(0.85-7.15)$ & 0.07 \\
\hline$\geq 55$ & 70 & 9 & 74 & 4 & $2.38(0.63-11.00)$ & 0.15 \\
\hline \multicolumn{7}{|l|}{ Sex } \\
\hline Female & 49 & 9 & 55 & 3 & $3.37(0.77-20.22)$ & 0.07 \\
\hline Male & 109 & 15 & 116 & 8 & $2.00(0.75-5.65)$ & 0.13 \\
\hline \multicolumn{7}{|c|}{ Alcohol drinkers } \\
\hline Never & 77 & 6 & 95 & 8 & $0.93(0.25-3.19)$ & 0.89 \\
\hline Ever & 81 & 18 & 76 & 3 & $5.63(1.54-30.76)$ & 0.003 \\
\hline \multicolumn{7}{|c|}{ Tobacco smoking } \\
\hline Never & 87 & 17 & 99 & 9 & $2.15(0.85-5.75)$ & 0.08 \\
\hline Ever & 71 & 7 & 72 & 2 & $3.55(0.64-35.88)$ & 0.10 \\
\hline \multicolumn{7}{|c|}{ Family history of cancer in the first relatives } \\
\hline No & 151 & 16 & 169 & 8 & $2.24(0.87-6.21)$ & 0.07 \\
\hline Yes & 7 & 8 & 2 & 3 & $0.76(0.05-8.98)$ & 0.80 \\
\hline \multicolumn{7}{|c|}{ Helicobacter pylori } \\
\hline Negative & 66 & 9 & 113 & 8 & $1.93(0.62-6.02)$ & 0.19 \\
\hline Positive & 92 & 15 & 58 & 3 & $3.15(0.83-17.61)$ & 0.07 \\
\hline
\end{tabular}




\section{DISCUSSION}

This case-control study explored the association of the rs11614913 polymorphism in pre-miR-196a2 and gastric cancer risk. We observed that the pre-miR-196a2 rs11614913 polymorphism was associated with a significantly increased risk of gastric cancer. In addition, rs11614913 interacts with the alcohol drinking habits in contributing to the development of gastric cancer in a Chinese population.

MiR-196 plays an important role in normal development and in the pathogenesis of human disease processes such as cancer (Chen et al., 2011). The miR-196 family is comprised of miR-196a-1, miR196a-2, and miR-196b. The miR-196a-1 and miR-196a-2 genes generate the same functional mature miRNA sequence miR-196a, whereas miR-196b produces a small RNA, which differs from the sequence of miR-196a by one nucleotide (Tanzer et al., 2005). By targeting its putative targets, such as the HOX, HMGA2, and annexin A1 genes, miR-196a could play important roles in tumorigenesis (Tanzer et al., 2005). Dysregulation of miR-196 expression has been reported in multiple cancer cell lines. Mature miR-196a is overexpressed in gastric cancer tissues, suggesting it also plays a role in the development of this type of cancer (Yao et al., 2009).

Only 3 studies have suggested that pre-miR-196a-2 rs11614913 contributes to pathogenesis of human cancers (Okubo et al., 2010; Wang et al., 2013; Dikeakos et al., 2014). Okubo et al. (2010) conducted a study in a Japanese population, and found that rs11614913 was correlated with the degree of $H$. pylori-induced mononuclear cell infiltration. Wang et al. (2013) reported that the rs11614913 polymorphism is correlated with the development of gastric cancer in a Chinese population. Dikeakos et al. (2014) also reported that rs 11614913 was correlated with an elevated risk of gastric cancer. However, two other studies reported that rs11614913 does not cause an increased risk of gastric cancer (Parlayan et al., 2014; Xu et al., 2015). One recent meta-analysis pooled six studies, and reported that rs 11614913 did not contribute to the development of gastric cancer (Zhang et al., 2015). Here, we found that the pre-miR-196a2 rs11614913 polymorphism did contribute to an increased risk of gastric cancer. The differences of the study results might be caused by differences in genetic background and by gene-environment interactions in the etiology of gastric cancer.

Our study has several limitations. Firstly, patients and controls were selected from a single hospital, and the selected controls may not be representative of the general population. Secondly, the sample size was relatively small, which may reduce the statistical power.

In conclusion, the results of our study suggest that the rs 11614913 gene polymorphism is associated with an elevated risk of gastric cancer, especially in drinkers. Future studies using larger sample sizes, and employing either similar or different analytical strategies may help to elucidate the role of rs11614913 in gastric cancer development.

\section{Conflicts of interest}

The authors declare no conflict of interest.

\section{REFERENCES}

Ang TL and Fock KM (2014). Clinical epidemiology of gastric cancer. Singapore Med. J. 55: 621-628. http://dx.doi. org/10.11622/smedj.2014174 
Chen C, Zhang Y, Zhang L, Weakley SM, et al. (2011). MicroRNA-196: critical roles and clinical applications in development and cancer. J. Cell. Mol. Med. 15: 14-23. http://dx.doi.org/10.1111/j.1582-4934.2010.01219.x

Daniyal M, Ahmad S, Ahmad M, Asif HM, et al. (2015). Risk factors and epidemiology of gastric cancer in Pakistan. Asian Pac. J. Cancer Prev. 16: 4821-4824. http://dx.doi.org/10.7314/APJCP.2015.16.12.4821

Dikeakos P, Theodoropoulos G, Rizos S, Tzanakis N, et al. (2014). Association of the miR-146aC $>$ G, miR-149T $>$ C, and miR-196a2T $>$ C polymorphisms with gastric cancer risk and survival in the Greek population. Mol. Biol. Rep. 41: 1075-1080. http://dx.doi.org/10.1007/s11033-013-2953-0

Fang C, Huang Q, Lu L, Shi J, et al. (2015). Risk factors of early proximal gastric carcinoma in Chinese diagnosed using WHO criteria. J. Dig. Dis. 16: 327-336. http://dx.doi.org/10.1111/1751-2980.12240

Graham DY and Yamaoka Y (2000). Disease-specific Helicobacter pylori virulence factors: the unfulfilled promise. Helicobacter 5 (Suppl 1): 3-9, discussion S27-S31. http://dx.doi.org/10.1046/j.1523-5378.2000.0050S1003.x

International Agency for Research on Cancer (2012). Stomach Cancer. Estimated Incidence, Mortality and Prevalence Worldwide in 2012. Available at [http://globocan.iarc.fr/Pages/fact_sheets_cancer.aspx]. Accessed on August 20, 2015.

Kamangar F, Abnet CC, Hutchinson AA, Newschaffer CJ, et al. (2006). Polymorphisms in inflammation-related genes and risk of gastric cancer (Finland). Cancer Causes Control 17: 117-125. http://dx.doi.org/10.1007/s10552-005-0439-7

Ni Q, Ji A, Yin J, Wang X, et al. (2015). Effects of two common polymorphisms rs2910164 in miR-146a and rs11614913 in miR-196a2 on gastric cancer susceptibility. Gastroenterol. Res. Pract. 2015: 764163. http://dx.doi. org/10.1155/2015/764163

Nikolić Z, Savić Pavićević D, Vučić N, Cidilko S, et al. (2015). Assessment of association between genetic variants in microRNA genes hsa-miR-499, hsa-miR-196a2 and hsa-miR-27a and prostate cancer risk in Serbian population. Exp. Mol. Pathol. 99: 145-150. http://dx.doi.org/10.1016/j.yexmp.2015.06.009

Okubo M, Tahara T, Shibata T, Yamashita H, et al. (2010). Association between common genetic variants in premicroRNAs and gastric cancer risk in Japanese population. Helicobacter 15: 524-531. http://dx.doi.org/10.1111/ j.1523-5378.2010.00806.x

Parlayan C, Ikeda S, Sato N, Sawabe M, et al. (2014). Association analysis of single nucleotide polymorphisms in miR146a and miR-196a2 on the prevalence of cancer in elderly Japanese: a case-control study. Asian Pac. J. Cancer Prev. 15: 2101-2107. http://dx.doi.org/10.7314/APJCP.2014.15.5.2101

Peng Q, Li S, Lao X, Chen Z, et al. (2014). The association of common functional polymorphisms in mir-146a and mir-196a2 and hepatocellular carcinoma risk: evidence from a meta-analysis. Medicine 93: e252. http://dx.doi. org/10.1097/MD.0000000000000252

Qi P, Wang L, Zhou B, Yao WJ, et al. (2015). Associations of miRNA polymorphisms and expression levels with breast cancer risk in the Chinese population. Genet. Mol. Res. 14: 6289-6296. http://dx.doi.org/10.4238/2015.June.11.2

Tanzer A, Amemiya CT, Kim CB and Stadler PF (2005). Evolution of microRNAs located within Hox gene clusters. $J$. Exp. Zoolog. B Mol. Dev. Evol. 304: 75-85. http://dx.doi.org/10.1002/jez.b.21021

Wang F, Sun GP, Zou YF, Fan LL, et al. (2013). Quantitative assessment of the association between miR-196a2 rs11614913 polymorphism and gastrointestinal cancer risk. Mol. Biol. Rep. 40: 109-116. http://dx.doi.org/10.1007/ s11033-012-2039-4

Wu Y, Hao X, Feng Z and Liu Y (2015). Genetic polymorphisms in miRNAs and susceptibility to colorectal cancer. Cell Biochem. Biophys. 71: 271-278. http://dx.doi.org/10.1007/s12013-014-0195-y

Xu Q, Liu JW and Yuan Y (2015). Comprehensive assessment of the association between miRNA polymorphisms and gastric cancer risk. Mutat. Res. Rev. Mutat. Res. 763: 148-160. http://dx.doi.org/10.1016/j.mrrev.2014.09.004

Yao Y, Suo AL, Li ZF, Liu LY, et al. (2009). MicroRNA profiling of human gastric cancer. Mol. Med. Rep. 2: 963-970.

Yuzhalin A (2011). The role of interleukin DNA polymorphisms in gastric cancer. Hum. Immunol. 72: 1128-1136. http:// dx.doi.org/10.1016/j.humimm.2011.08.003

Zhang L, Gao J, Zhou D and Bao F (2015). Lack of association of two common polymorphisms rs2910164 and rs11614913 with susceptibility to gastric cancer: A meta-analysis. Turk. J. Gastroenterol. 26: 378-385. http://dx.doi.org/10.5152/ tjg.2015.6603 